\title{
Vitrectomia farmacológica e descolamento do vítreo posterior
}

\author{
Pharmacological vitreolysis and posterior vitreous detachment
}

\author{
Leonardo Bruno Oliveira ${ }^{1}$ \\ Rodrigo Jorg'e ${ }^{2}$ \\ Rogério Alves Costa ${ }^{3}$ \\ José Auǵusto Cardillo ${ }^{3}$ \\ Rubens Camargo Siqueira ${ }^{3}$
}

\section{RESUMO}

O vítreo exerce papel crucial na patogênese de vários distúrbios vitreoretinianos. As alterações moleculares e estruturais fisiológicas do gel vítreo evoluem para a liquefação e culminam com o descolamento do córtex vítreo posterior (DVP). A ocorrência do descolamento do vítreo posterior influencia positivamente o prognóstico de pacientes diabéticos, com maculopatias e vasculopatias. Abordaremos o conceito da vitrectomia farmacológica que se refere ao uso de agentes que alteram a organização molecular do vítreo, num esforço de reduzir ou eliminar seu papel na gênese de doenças vítreoretinianas, sendo o seu objetivo final, o descolamento total do vítreo posterior. Vários agentes têm sido estudados durante a última década, porém, existem várias limitações na aplicabilidade clínica destes compostos. Nesse artigo de revisão, iremos abordar os diferentes agentes e os seus mecanismos de ação sobre a matriz extracelulare a interface vítreo-retiniana.

Descritores: Vitrectomia; Descolamento do vítreo; Corpo vítreo/efeitos de droga; Matriz extracelular; Doenças retinianas/quimioterapia

\section{INTRODUÇÃO}

Descolamento do vítreo posterior (DVP) pode ser definido como a separação da região cortical do vítreo posterior da membrana limitante interna da retina (MLI). Pesquisas realizadas a partir de necrópsias relatam a incidência de DVP em $63 \%$ dos olhos estudados na oitava década de vida $^{(1)}$. O DVP é mais comum em mulheres e em míopes, ocorrendo dez anos mais cedo nestes casos do que em emétropes e hipermétropes. A cirurgia de catarata também pode abreviar o aparecimento de DVP, principalmente em pacientes míopes ${ }^{(2)}$.

O DVP resulta do enfraquecimento da adesão do córtex vítreo com a Trabalho realizado no Setor de Retina e Vítreo do Departamento de Oftalmologia, Otorrinolaringologia, e Cirurgia de Cabeça e Pescoço do Hospital das Clínicas da Faculdade de Medicina de Ribeirão Preto da Universidade de São Paulo - USP.

${ }^{1}$ Pós-graduando da Faculdade de Medicina de Ribeirão Preto da Universidade de São Paulo (FMRP-USP).

${ }^{2}$ Professor Doutor do Departamento de Oftalmologia, Otorrinolaringologia e Cirurgia de Cabeça e Pescoço da Faculdade de Medicina de Ribeirão Preto da Universidade de São Paulo (FMRP-USP).

${ }^{3}$ Médico Colaborador do Hospital das Clínicas das Clínicas da Faculdade de Medicina de Ribeirão Preto da Universidade de São Paulo (FMRP - USP).

Endereço para correspondência: Leonardo Bruno Oliveira, Av. Marcos de Freitas Costa, 855 - Uberlândia (MG) CEP 38400-328

E-mail: leonardobruno@hobc.com.br

Recebido para publicação em 06.10.2004 Aprovação em 10.11.2004 MLI, em conjunto com a liquefação vítrea que ocorre com o avanço da idade. Ao processo de liquefação vítrea denominamos sínquise. Postula-se que o vítreo liquefeito atinja o espaço posterior ao córtex vítreo através de uma abertura deste, localizada na região imediatamente anterior ao disco óptico (área de Martegiani) ${ }^{(3)}$. Com o movimento do corpo e conseqüentemente da cabeça e dos olhos, o vítreo liquefeito vagarosamente disseca o espaço retro-cortical, aumentando a área de descolamento do córtex vítreo da MLI. O DVP acontece, então, quando a adesão vítreo-retiniana é rompida, havendo um colapso do corpo vítreo totalmente separado da retina, em um processo denominado de sinérese ${ }^{(4)}$.

O DVP total caracteriza-se pela completa separação entre o vítreo cortical posterior e a retina (sem áreas residuais de adesão em superfície retiniana). A ocorrência do DVP total em pacientes com vasculopatias da retina 
garante que não haverá descolamento de retina tracional ${ }^{(5)}$. Dentre as vasculopatias, destacam-se a retinopatia diabética, as oclusões venosas e arteriais de vasos da retina, a doença de Eales. Estas doenças caracterizam-se pelo desenvolvimento de neovasos de retina, que rompem a membrana limitante interna e crescem ancorados ao vítreo cortical posterior. Os neovasos são seguidos pela formação de tecido fibrótico, cuja contração traciona a retina em direção ao vítreo, originando o descolamento de retina tracional. Nos casos em que há DVP total, os neovasos retinianos não se ancoram ao vítreo e, conseqüentemente, não levam ao descolamento de retina.

O DVP também pode ser benéfico em casos de buracos maculares idiopáticos. Estudos com a utilização da tomografia de coerência óptica têm demonstrado a importância da tração ântero-posterior do vítreo sobre a retina na gênese do buraco macu$\operatorname{lar}^{(6)}$. Em recente relato ${ }^{(7)}$, uma injeção de perfluoropropano foi capaz de induzir o DVP, removendo a tração ântero-posterior e levando à regressão um caso de buraco macular grau II.

O DVP pode ser realizado de modo mecânico pela vitrectomia via pars plana, em que, utilizando-se manobras de alta sucção, inicia-se o descolamento da hialóide na borda papilar e progride-se centrifugamente por toda a superfície retiniana até a base vítrea. Todavia, apesar de ser altamente eficaz, a cirurgia pode causar roturas retinianas e sangramentos, além de eventualmente deixar ilhas de hialóide posterior ainda aderidas à retina. Remanescentes da hialóide posterior podem servir de superfície para a proliferação vítreo-retiniana e posterior contração fibrocelular e descolamento tracional de retina. Por esta razão, ultimamente têm sido descritas alternativas menos invasivas, como a injeção de enzimas e gases, com o intuito de se induzir o descolamento total de vítreo posterior ${ }^{(7-8)}$. Uma dessas alternativas é a vitrectomia farmacológica.

O termo vitrectomia farmacológica refere-se ao uso de agentes que alteram a organização molecular do vítreo, num esforço em reduzir ou eliminar seu papel na gênese de doenças vítreo-retinianas. O objetivo final da vitrectomia farmacológica é o descolamento total do vítreo posterior. Vários são os fármacos utilizados atualmente, dentre os quais destacamos a hialuronidase, a dispase, a condroitinase, a plasmina, o peptídeo RGD e o perfluoropropano.

\section{1- Hialuronidase}

Desde 1949 esta enzima tem sido usada em trabalhos experimentais na liquefação do gel vítreo ${ }^{(9)}$. Trata-se de um agente que atua na degradação do ácido hialurônico, importante componente do arcabouço vítreo. Uma forma purificada da enzima utilizada no passado, denominada Vitrase ${ }^{\circledR}$, tem sido empregada na Fase III de um estudo aprovado pelo "Food and Drug Administration" (FDA), para determinar sua eficácia no clareamento vítreo de pacientes diabéticos com hemorragia vítrea sem a intervenção cirúrgica ${ }^{(10)}$. Tal abordagem desperta muito interesse clínico, uma vez que pacientes com retinopatia diabética não proliferativa ou proliferativa incipiente poderiam se beneficiar da liquefação precoce e indução indireta do
DVP e, portanto, apresentar melhor prognóstico na evolução da retinopatia, como acima comentado.

Inicialmente, foi proposta a sua utilização na indução do descolamento do vítreo posterior, apesar da existência de pequena base teórica para a confirmação desta hipótese. Observou-se que a hialuronidase não apresentava influência direta em estruturas moleculares presentes na interface vítreoretiniana. Entretanto, em séries clínicas de pacientes tratados com hialuronidase intravítrea, o mesmo grupo apresentou aumento na incidência do descolamento do vítreo posterior, possivelmente secundário à inflamação intra-ocular provocada pela injeção intravítrea da enzima. Contudo, se o vítreo mantém-se fortemente aderido à superfície retiniana, por meio da indução farmacológica de um processo de sinerése não fisiológica, pode-se desencadear roturas retinianas iatrogênicas. Portanto, são fortes as evidências de que a hialuronidase promove a liquefação vítrea, porém apresenta limitada ação na interface vítreo-retiniana e não é eficaz para induzir o descolamento vítreo posterior.

No contexto atual, vemos utilização potencial dessa enzima como adjuvante em procedimentos cirúrgicos vítreos de pequena incisão, facilitando a liquefação vítrea pré e peroperatória e, conseqüentemente, a redução do tempo e aumento da eficácia desses procedimentos.

\section{2- Plasmina}

Atualmente, a plasmina é uma das enzimas mais estudadas em vitrectomia farmacológica e com grande potencial de sua utilização em estudos clínicos ${ }^{(11-13)}$. Trata-se de uma enzima não específica que tem afinidade por laminina e fibronectina, dois componentes da matriz extra-celular (MEC) presentes na membrana limitante interna, sabidamente uma estrutura implicada na adesão da interface vítreo-retiniana.

Verstraten et al. ${ }^{(11)}$, em estudo experimental pioneiro (olhos de coelhos), evidenciaram que a utilização de plasmina intravítrea se mostrou útil adjuvante à cirurgia de vitrectomia na indução de descolamento do vítreo posterior. Subseqüentemente, Margherio et al. ${ }^{(12)}$ apresentaram uma série de casos (buracos de mácula traumáticos em pacientes pediátricos) em que a plasmina facilitou a indução cirúrgica do DVP. No entanto, a plasmina utilizada nesses primeiros estudos foi de origem bovina, o que causou dificuldade na aprovação de protocolos e instalação de estudos multicêntricos. Com isso, o grupo do Dr. Trese, preconizador de sua utilização ${ }^{(13)}$, desenvolveu um "kit" para a obtenção da plasmina autóloga e a sua subseqüente utilização durante o procedimento cirúrgico.

Existe em andamento um estudo clínico desenvolvido por dois centros americanos (Royal Oak, MI e Durham, NC), para avaliação da plasmina autóloga durante a cirurgia de vitrectomia para buraco de mácula graus 2 e 3 * (comunicação pessoal).

Em estudos experimentais preliminares realizados por nós em 2001 (dados não publicados), utilizando o "kit" para obten-

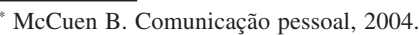


ção de plasmina autóloga, foram observados sinais de liquefação vítrea 30 minutos após a injeção enzimática. Além da hidrólise de glicoproteínas da interface vítreo-retiniana, existem hipóteses baseadas em evidências científicas de que a plasmina seja responsável também pela liquefação vítrea, pela ativação de metaloproteinases (enzimas intrínsecas à cavidade vítrea responsáveis pelo processo fisiológico de sinerése vítrea).

Outro estudo experimental, associando a plasmina com a injeção de gás ("SF6"), apresentou resultados interessantes quanto à eficácia na indução do DVP, em comparação com a injeção isolada de gás intravítreo ${ }^{(14)}$.

Recentemente, foi publicado um estudo experimental realizado pelo grupo de pesquisadores da Tulane Universtity, em que foi utilizada a tecnologia recombinante, na produção de plasmina dentro da cavidade vítrea (pela injeção intravítrea de plasminogênio e urocinase), associada com a injeção de SF6, reproduzindo resultados similares a estudos anteriores e tendo como vantagens a praticidade em sua obtenção e a esterili$\operatorname{dade}^{(13)}$.

\section{3- Dispase}

A dispase é uma enzima com atividade proteolítica contra fibronectina e colágeno do tipo 4, componentes que, juntamente com a laminina, constituem a estrutura molecular da membrana limitante interna ${ }^{(15)}$.

Estudos preliminares demonstraram que sua ação de relativa especificidade nos componentes da junção vítreo-retiniana se traduziu na ruptura de fibras colágenas na lâmina delgada externa e na preservação da lâmina densa da MLI. Logo, os investigadores concluíram que a dispase não induziria efeitos colaterais na retina, uma vez que as extensões das células de Muller permaneceram intactas ${ }^{(16)}$.

Em 2001, nossos estudos, em colaboração com McCuen, em olhos de suínos jovens (em que existe forte adesão vítreoretiniana) confirmaram evidências preliminares de que a dispase facilitava a separação do vítreo posterior na indução mecânica durante vitrectomia via "pars plana". Também não se evidenciaram, em pós-operatório, alterações eletrorretinográficas ou histológicas do tecido retiniano dos suínos ${ }^{(8)}$.

No entanto, estudos realizados pelo nosso grupo em animais e humanos, constataram a ocorrência de hemorragias retinianas nas doses relatadas no trabalho original de Tezel et al. A presença de hemorragias sugere que a dispase também é capaz de digerir a membrana basal dos capilares da retina, não sendo específica para os componentes da junção vítreoretiniana ${ }^{(17)}$.

Portanto, até o momento há evidências de que a dispase possa facilitar o DVP, quando usada como adjuvante durante a vitrectomia mecânica (tempo de exposição de 15 minutos) na dose de 0,04 UI. Entretanto, nossos estudos mostram que a mesma não é segura nas doses de 2,5 UI por 30 minutos e na dose de 0,05 UI por 30 dias. Por fim, não há evidências de que a injeção intravítrea de dispase, sem vitrectomia, possa induzir ao DVP “in vivo".

\section{4- Condroitinase}

No início da década de 90, estudos de imunofluorescência detectaram intensa reatividade de anticorpos ao sulfato de condroitinase na interface vítreo-retiniana de olhos de macacos e humanos, principalmente em região peripapilar e base vítrea. Tais evidências levaram a estudos pilotos ("in vivo" em olhos de macacos e olhos de doadores humanos) que documentaram a eficácia da condroitinase no descolamento de base vítrea como adjuvante à vitrectomia ${ }^{(18)}$.

No final da década de 90 foi concluída a fase I do estudo clínico, mas os resultados não foram publicados, e a fase II ainda não foi iniciada.

\section{5- Peptídeo RGD}

Diferentemente dos demais agentes estudados, trata-se de um peptídeo sintético de cadeia curta (Gly-Arg-Gly-Glu-SerThr-Pro) que, em associação à cirurgia vítreo-retiniana em olhos de coelhos, foi descrito por nosso grupo em 2002, com o propósito de sua utilização no campo da vitrectomia farmacológica ${ }^{(19)}$.

Como foi abordado anteriormente, apesar da evolução dos conhecimentos sobre a adesão vítreo-retiniana, a compreensão de sua fisiologia ainda não está totalmente esclarecida. De acordo com estudos histológicos, as fibras colágenas corticais ancoram-se na MLI, adjacente aos pedículos da célula de Muller, na superfície interna da retina ${ }^{(20)}$. Sabemos também que a MEC é uma componente crítico na mediação da adesão celular, inclusive da interface vítreo-retiniana ${ }^{(21)}$. Por outro lado, os principais sítios de ligação entre a MEC e a célula são os receptores da superfície celular, chamados integrinas ${ }^{(22-23)}$. Contudo, as seqüências de ligação Arg-Gly-Asp (seqüência RGD), incorporadas às diferentes moléculas da MEC, são as responsáveis pela interação com as integrinas. Já do lado celular, as integrinas são altamente ligadas à fibronectina e à laminina, através das sequiências de ligação, que são exatamente as constituintes da MLI presentes na interface vítreo-retiniana ${ }^{(24)}$.

Portanto, a injeção do peptídeo RGD funciona como um análogo sintético, competindo com as seqüências de ligação específicas da MEC, provocando um relaxamento da interação entre as integrinas-MEC, e consequientemente enfraquecendo a adesão da interface vítreo-retiniana ${ }^{(25-26)}$.

Apesar desse estudo controlado não abordar aspectos de toxicidade e potencial antigenicidade relacionados com o peptídeo utilizado, abrem-se novas perspectivas na abordagem e conceito da vitrectomia farmacológica.

\section{6- Perfluorpropano (C3F8)}

Uma abordagem alternativa em vitrectomia farmacológica, que tem sido discutida recentemente, é a utilização intravítrea de gás expansível, como o perfluoropropano $(\mathrm{C} 3 \mathrm{~F} 8)^{(27)}$. Com o auxílio da tomografia de coerência óptica, Costa et al. ${ }^{(7)}$ demonstraram a influência positiva na evolução de buraco de mácula estágio II após a injeção intravítrea de $\mathrm{C} 3 \mathrm{~F} 8$, e relaxamento de tração foveolar ântero-posterior por subseqüente separação do vítreo cortical. 
Postula-se que os efeitos produzidos pela injeção de gás intravítreo na estrutura molecular do vítreo são principalmente relacionados à ação mecânica provocando inicialmente uma compressão do gel vítreo, seguida de sua liquefação. Com o tempo o vítreo liqüefeito infiltra-se pela região anterior ao disco óptico, dissecando o córtex vítreo posterior da MLI. Com a redução do volume da bolha de gás, o vítreo descomprimido se colapsa e se desinsere totalmente da retina. Em estudo experimental ${ }^{(14)}$, Hikichi et al. obtiveram resultados interessantes utilizando a combinação de hialuronidase e hexafluoreto de enxofre (SF6) em olho de coelhos. A combinação entre um efeito químico (hialuronidase) e físico (SF6) teve como objetivo promover concomitantemente a liquefação do vítreo e a separação do vítreo cortical, demonstrando assim maior incidência do descolamento do vítreo posterior quando comparada à dos grupos em que foram utilizadas isoladamente enzima ou SF6.

Para finalizar, entendemos que o agente ideal seria aquele que enfraquecesse ou clivasse a junção vítreo-retiniana antes ou simultaneamente à liquefação vítrea. No entanto, até o momento, nenhum dos agentes possui eficácia clinicamente comprovada, apesar de alguns resultados promissores acima citados. Estudos adicionais ainda são necessários para consolidar o uso desses agentes e da associação dos mesmos, permitindo assim que a vitrectomia farmacológica seja definitivamente incorporada à rotina da clínica oftalmológica.

\section{ABSTRACT}

The vitreous plays an important role in the pathogenesis of several vitreoretinal diseases. The physiological molecular and structural modifications of the vitreous gel lead to liquefaction and posterior vitreous detachment, which positively influence the vision of patients with diabetic retinopathy, maculopathies and vasculopathies. This review article will approach the concept of pharmacological vitreolysis that refers to the use of different agents, which modify the molecular vitreous organization, in order to reduce or eliminate its role in the genesis of several vitreoretinal diseases, having a posterior vitreous detachment as its final goal. In the last decade, several agents have been extensively studied but there are some limitations in their clinical applicability. We will discuss such agents and their effects on different sites of the vitreoretinal extracellular matrix and vitreoretinal interface.

Keywords: Vitrectomy; Vitreous detachment; Vitreous body/ drug effects; Extracellular matrix; Retinal diseases/drug therapy

\section{REFERÊNCIAS}

1. Foos RY. Posterior vitreous detachment. Trans Am Acad Ophthalmol Otolaryngol. 1972;76(2):480-97.
2. Hyams SW, Neumann E, Friedman Z. Myopia and aphakia II. Vitreous and peripheral retina. Br J Ophthalmol. 1975;59(9):483-85.

3. Eisner G. Posterior vitreous detachment. Klin Monatsbl Augenheilkd. 1989; 194(5):389-92. Germany.

4. Sebag J. Ageing of the vitreous. Eye. 1987;1(Pt 2):254-62.

5. Sebag J. Diabetic vitreopathy. Ophthalmology. 1996;103(2):205-6. Comment on: Ophthalmology. 1996;103(2):315-22.

6. Tanner V, Chauhan DS, Jackson TL, Williamson TH. Optical coherence tomography of the vitreoretinal interface in macular hole formation. Br J Ophthalmol. 2001;85(9):1092-7.

7. Costa RA, Cardillo JA, Morales PH, Jorge R, Uno F, Farah ME. Optical coherence tomography evaluation of idiophathic macular hole treatment by gasassisted posterior vitreous detachment. Am J Ophthalmol. 2001;132(2): 264-6.

8. Oliveira LB, Tatebayashi M, Mahmoud TH, Hao Y, Petters RM, Wong F, et al. Dispase-assisted vitrectomy facilitates posterior vitreous detachment in young porcines[abstract]. Invest Ophthalmol Vis Sci. 2000;41(Suppl):344.

9. Pirie A. Effect of hyaluronidase injection on vitreous humor of rabbit. Br J Ophthalmol. 1949;33(11):678-84.

10. Kuppermann BD, Thomas EL, Grillone LR, Chandler JW. Ovine hyaluronidase (Vitrase ${ }^{\circledR}$, an investigational drug) reduces vitreous hemorrhage density (RVHD) and improves best corrected visual acuity (BCVA): integrated results from 2 Phase III studies [abstract]. Invest Ophthalmol Vis Sci. 2004;45 (suppl): 1947 .

11. Verstraeten TC, Chapman C, Hatzer M, Winkler BS, Trese MT, Williams GA. Pharmacologic induction of posterior vitreous detachment in the rabbit. Arch Ophthalmol. 1993;111(6):849-54.

12. Margherio AR, Margherio RR, Hartzer M, TreseMT, Williams GA, Ferrone PJ. Plasmin enzyme-assisted vitrectomy in traumatic pediatric macular holes. Ophthalmology. 1998;105(9):1617-20.

13. Men G, Peyman GA, Genaidy M, Kuo PC, Ghahramani F, Blake DA, et al. The role of recombinant lysine-plasminogen and recombinant urokinase and sulfur hexafluoride combination in inducing posterior vitreous detachment. Retina. 2004;24(2):199-209.

14. Hikichi T, Yanagiya N, Kado M, Akiba J, Yoshida A. Posterior vitreous detachment induced by injection of plasmin and sulfur hexafluoride in the rabbit vitreous. Retina. 1999;19(1):55-8.

15. Stenn KS, Link R, Moellmann G, Maori J, Kuklinska E. Dispase, a neutral protease from Bacillus polymyxa, is a powerful fibronectinase and type IV collagenase. J Invest Dermatol. 1989;93(2):287-90.

16. Tezel TH, Del Priore LV, Kaplan HJ. Posterior vitreous detachment with dispase. Retina. 1998;18(1):7-15.

17. Jorge R, Oyamaguchi EK, Cardillo JA, Gobbi A, Laicine EM, Haddad A. Intravitreal injection of disease causes retinal hemorrhages in rabbit and human eyes. Curr Eye Res. 2003;16(2):107-12.

18. Hageman GS, Russel SR. Chondroitinase-mediated disinsertion of the primate vitreous body [abstract]. Invest Ophthalmol Vis Sci. 1994;35 (suppl):1260.

19. Oliveira LB, Meyer CH, Kumar J, Tatebayahi M, Toth CA, Wong F, et al. RGD peptide-assisted vitrectomy to facilitate induction of a posterior vitreous detachment: a new principle in pharmacological vitreolysis. Curr Eye Res. 2002;25(6):333-40.

20. Sebag J. Anatomy and pathology of the vitreo-retinal interface. Eye. 1992;6 (Pt 6):541-52.

21. Russell SR, Shepherd JD, Hageman GS. Distribution of glycoconjugates in the human retinal internal limiting membrane. Invest Ophthalmol Vis Sci. 1991;32(7):1986-95.

22. Ingber D. Integrins as mechanochemical transducers. Curr Opin Cell Biol. 1991;3(5):841-8.

23. Elner SG, Elner VM. The integrin superfamily and the eye. Invest Ophthalmol Vis Sci. 1996;37(5):696-701.

24. Ruoslahti E. Integrins. J Clin Invest 1991;87(5):1-5.

25. Pierschbacher MD, Ruoslahti E. Influence of stereochemistry of the sequence Arg-Gly-Asp-Xaa on binding specificity in cell adhesion. J Biol Chem. 1987; 262(36): 17294-8.

26. Williams JA. Disintegrins: RGD-containing proteins which inhibit cell/matrix interactions (adhesion) and cell/cell interactions (aggregation) via the integrin receptors. Pathol Biol. 1992;40(8):813-21.

27. Chan CK, Wessels IF, Friedrichsen EJ. Treatment of idiopathic macular holes by induced posterior vitreous detachment. Ophthalmology. 1995;102(5):757-67. 